Tạp chí Khoa học và Công nghệ biển T10 (2010). Số 4. Tr 29 - 37

\title{
BÀN VỀ NGUỒN GỐC QUẶNG TITAN Ở VÙNG BỜ QUẢNG NAM
}

\author{
TRỊNH THẾ HIẾU, ĐỖ MINH TIỆP, PHẠM BÁ TRUNG
}

Viện Hải dương học

\begin{abstract}
Tóm tắt: Các mẫu đá cát kết quặng Ti thu được tại các tu khoáng Duy Nghĩa, (huyện Duy Xuyên), Tam Hiệp, Tam Nghĩa và Tam Hải (huyện Núi Thành), tỉnh Quảng Nam là khá độc đáo và hiếm gặp tại các mỏ sa khoáng cũng nhu các tụ khoáng dọc ven bò̀ Quảng Nam nói riêng và ven bờ miền Trung nói chung.

Thành phần khoáng của đá bao gồm: Thạch anh, các khoáng vật sắt, các khoáng vật titan gắn với nhau bởi keo sắt. Các keo sắt này có thể được tạo thành trong quá trình phong hóa đá. Trong thành phần đá, các khoáng vật quặng chiếm uu thế, cho nên tạo ra sụ sẫm màu của đá.

Chính lớp đá cát kết quạng Ti này, là một trong nhũng nguồn tiếp quan trọng cho các tu khoáng Ti trong vùng bò̀ Quảng Nam.
\end{abstract}

\section{I. ĐẶT VẤN Đî̀}

Khai thác quặng titan (Ti) khá phổ biến ở nước ta. Quặng Ti đang khai thác nằm ở các đụn cát và các bãi ở vùng ven biển từ Hà Tĩnh đến Vũng Tàu, nơi nhiều nhất là dọc theo ven bờ biển miền Trung, từ Thừa Thiên - Huế đến Phú Yên. Tuy nhiên, việc khai thác quặng Ti ở các khu vực này, phần lớn còn mang tính chất tự phát, kiểu "hái lượm", nơi nào thấy có quặng là khai thác, chứ không có quy hoạch, không có nghiên cứu cơ bản để đánh giá trữ lượng, chất lượng và tìm hiểu nguồn gốc thành tạo quặng.

Những năm gần đây, việc nghiên cứu sâu về thành phần vật chất và nguồn cung cấp quặng sa khoáng đã bắt đầu được chú ý, nhằm phục vụ tốt hơn cho công tác tìm kiếm, đánh giá sa khoáng vùng bờ và biển ven bờ.

Trong các chuyến khảo sát vùng bờ tỉnh Quảng Nam (12/2005, 10/2006, 1/2008), trong phạm vi các đụn cát trong cùng của khu vực Tam Hiệp đến Tam Nghĩa, ven bờ biển Tam Hải, huyện Núi Thành và khu vực thôn 5 , xã Duy Nghĩa, Duy Xuyên, nơi một số Công ty của Quảng Nam, đang khai thác cát quặng Ti, chúng tôi đã thu được các mẫu quặng Ti, là dạng đá cứng trong đá cát kết, nằm ở dưới chân các đụn cát.

Việc nghiên cứu chi tiết các mẫu đá này, là nhằm góp phần vào việc lý giải nguồn gốc quặng Ti ở các tụ khoáng trong phạm vi vùng bờ Quảng Nam nói riêng và của cả dải 
ven biển miền Trung nói chung. Đồng thời bằng phương pháp so sánh, có thể định hướng cho việc tìm kiếm quặng Ti, tại các khu vực có bối cảnh địa chất tương tự.

\section{PHƯƠNG PHÁP NGHIÊN CỨU}

\section{Phương pháp phân tích}

\subsection{Phân tích hóa học}

Tiến hành theo quy phạm "Điều tra địa chất biển" (1982). Mẫu được nung chảy với $\mathrm{Na}_{2} \mathrm{CO}_{3}$ và xử lý với axit $\mathrm{HCl}$. Hàm lượng $\mathrm{Fe}$ tổng số được xác định bằng phương pháp chuẩn độ. Hàm lượng Ti và $\mathrm{Mn}$ được xác định bằng phương pháp so màu.

\subsection{Phân tích thạch học}

Dựa theo tài liệu hướng dẫn của Meurig P. Jones and Marston G. Fleming, 1965. Mẫu nguyên khối được soi trên kính lúp MBS - 2, có độ phóng đại 14 lần. Mẫu được đập ra để có được mẫu ở dạng bở rời rồi được soi trên kính MBS - 9, có độ phóng đại 56 lần.

\section{Phương pháp so sánh, đánh giá}

\section{1. Đánh giá trữ lượng}

Dựa theo tài liệu khoáng sàng của P.M. Tatarinov và A.E. Karyakin đồng chủ biên.

\subsection{Luận giải về quá trình thành tạo quặng Ti}

Dựa theo tài liệu "Địa chất khoáng sản có ích” của V.I. Smirnov.

\section{KẾT QUẢ NGHIÊN CÚU}

\section{Hiện trạng khai thác cát quặng Ti tại các tụ khoáng và điểm quặng.}

\section{Tụ khoáng Duy Nghĩa và Duy Hải, huyện Duy Xuyên}

Cho đến nay trữ lượng của 2 điểm quặng này vẫn được chưa đánh giá. Phương pháp khai thác lộ thiên. Tại khu vực mũi An Lương, Duy Hải, sản lượng khai thác của năm 2005 là 7.000 tấn/năm, còn tại thôn 5, Duy Nghĩa (mới khai thác từ đầu tháng 12/2005) sản lượng ước đạt khoảng 3 tấn/ngày. Sản phẩm chính là inmenit và rutil. 


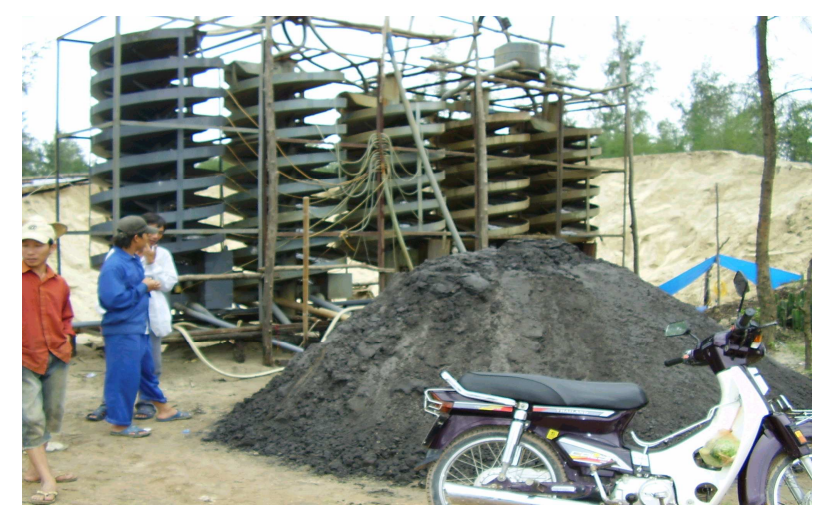

Ảnh 1: Khai thác cát quặng Ti của Công ty ĐT \& PT Kỳ Hà tại tụ khoáng Duy Nghĩa

\section{Tụ khoáng Tam Hiệp}

Xã Tam Hiệp, H. Núi Thành nằm trong phạm vi quy hoạch của khu kinh tế mở Chu Lai. Chính vì vậy việc khai thác cát quặng Ti tại khu vực đụn cát cổ dọc theo quốc lộ IA, ở phía Tây địa phận của xã này, không chỉ với mục đích khai thác tài nguyên khoáng sản, mà còn tạo mặt bằng chuẩn bị để xây dựng các khu công nghiệp hay một khu đô thị mới trong tương lai.

Tụ khoáng do Công ty Vạn Thông, Quảng Nam khai thác, theo giấy phép do Sở Tài nguyên - Môi trường Quảng Nam cấp năm 2005. Phương pháp khai thác lộ thiên (Ảnh 2). Độ sâu khai thác $4-5 \mathrm{~m}$, so với độ cao của đỉnh đụn cát - tức là xuống đến bề mặt của lớp phong hóa cát kết quặng Ti. Do chỉ mới bắt đầu khai thác từ vài tháng cuối năm 2005 và việc khai thác lại chỉ mang tính chất tận thu (hàm lượng các khoáng vật quặng thường $<0.5 \%$ ), nên sản lượng khai thác (đến thời điểm khảo sát 12/2005) ước tính đạt khoảng $400-500$ tấn.

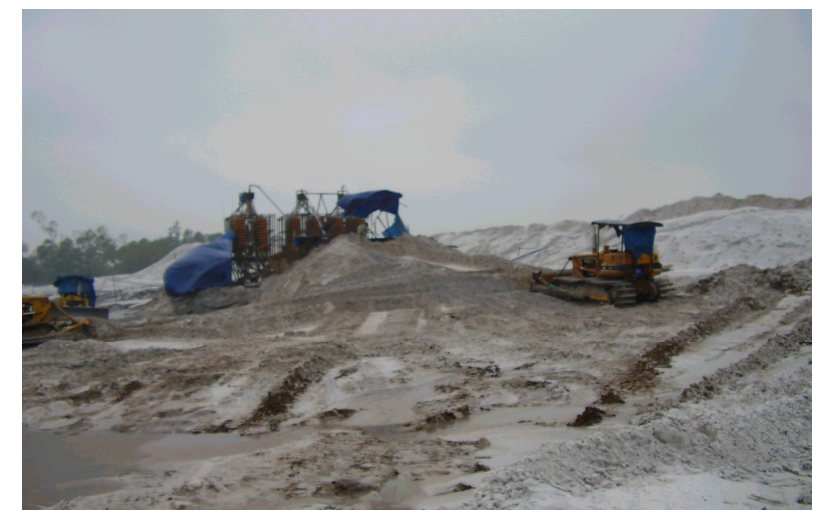

Ảnh 2: Khai thác cát quặng Ti của Công ty Vạn Thông tại tụ khoáng Tam Hiệp 


\section{Tụ khoáng Tam Nghĩa}

Trong phạm vi địa phận xã Tam Nghĩa, hiện có hai điểm đang được khai thác: một điểm do Công ty cổ phần Đất Quảng khai thác (ảnh 2) và một điểm do Doanh nghiệp tư nhân Phước Toàn khai thác. Cả hai đơn vị này đều được cấp giấy phép khai thác vào đầu năm 2006. Cũng giống như ở tụ khoáng Tam Hiệp, phương pháp khai thác tại các điểm tụ khoáng này là khai thác lộ thiên và cũng chỉ mang tính tận thu, nên sản lượng tính đến thời điểm chúng tôi khảo sát (10/2006), chỉ đạt 150 - 200 tấn. Điểm khác biệt với tụ khoáng Tam Hiệp là, độ sâu khai thác có nơi xuống tới độ sâu 10-12m, so với đỉnh đụn và cũng chính là bề mặt của lớp phong hóa cát kết quặng Ti.

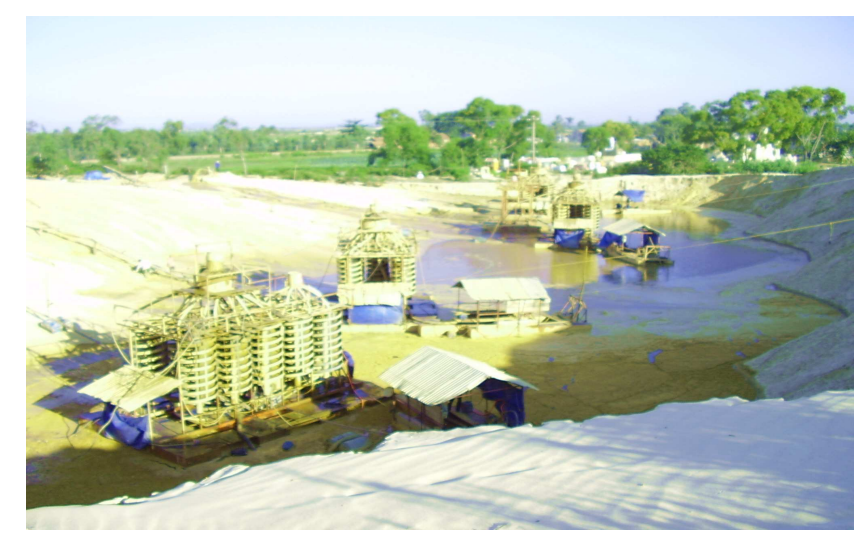

Ảnh 3: Khai thác cát quặng Ti của CTCP Đất Quảng tại tụ khoáng Tam Nghĩa

\section{2. Đặc điểm đá cát kết quặng Ti}

\subsection{Vị trí phân bố}

Bảng 1: Địa điểm và vị trí thu mẫu

\begin{tabular}{|c|c|c|c|c|c|}
\hline \multirow{2}{*}{$\begin{array}{c}\text { Ký hiệu } \\
\text { mẫu }\end{array}$} & \multicolumn{2}{|c|}{ Tọa độ địa lý } & \multirow{2}{*}{$\begin{array}{c}\text { Tên gọi } \\
\text { mẫu }\end{array}$} & \multirow{2}{*}{ Vị trí thu mẫu } & \multirow{2}{*}{ Địa điểm } \\
\hline & Vĩ độ & Kinh độ & & & \\
\hline THi. - 01 & $15^{\circ} 27^{\prime} 25.75^{\prime \prime}$ & $108^{\circ} 36^{\prime} 23.40^{\prime \prime}$ & Đá cát kết & $\begin{array}{l}\text { Chân đụn } \\
4 \text { - } 6 \text { m }\end{array}$ & Tam Hiệp \\
\hline TNg. - 02 & $15^{\circ} 24^{\prime} 20.33^{\prime \prime}$ & $108^{\circ} 41^{\prime} 03.62^{\prime \prime}$ & Đá cát kết & $\begin{array}{l}\text { Chân đụn } \\
10 \text { - } 12 \text { m }\end{array}$ & Tam Nghĩa \\
\hline THa.- 03 & $15^{\circ} 29^{\prime} 46.71^{\prime \prime}$ & $108^{\circ} 39^{\prime} 26.51^{\prime \prime}$ & Đá cát kết & $\begin{array}{l}\text { Chân đụn } \\
10 \text { - } 12 \text { m }\end{array}$ & Tam Hải \\
\hline DNg. - 04 & $15^{\circ} 52^{\prime} 01.16^{\prime \prime}$ & $108^{\circ} 23^{\prime} 29.56^{\prime \prime}$ & Đá cát kết & $\begin{array}{l}\text { Chân đụn } \\
10 \text { - } 12 \text { m }\end{array}$ & Duy Nghĩa \\
\hline
\end{tabular}


Các mẫu được thu trong các chuyến khảo sát vùng ven bờ biển tỉnh Quảng Nam (12/2005, 10/2006 và 1/2008), trong phạm vi các đụn cát trong cùng của khu vực Tam Hiệp đến Tam Nghĩa, huyện Núi Thành, nơi một số Công ty đang khai thác cát quặng Ti. Các địa điểm và vị trí thu mẫu được thể hiện trong bảng 1 . Vị trí thu mẫu tại khu vực thuộc xã Tam Hiệp là dưới chân đụn cát trong cùng có độ cao 4 - 6 m; tại các tụ khoáng Tam Nghĩa là dưới chân chân đụn cát cát, cao 10 - 12 m (ảnh 4). Ngoài ra, các mẫu tương tự còn thu được tại khu vực thôn 5, Duy Nghĩa. Duy Xuyên.

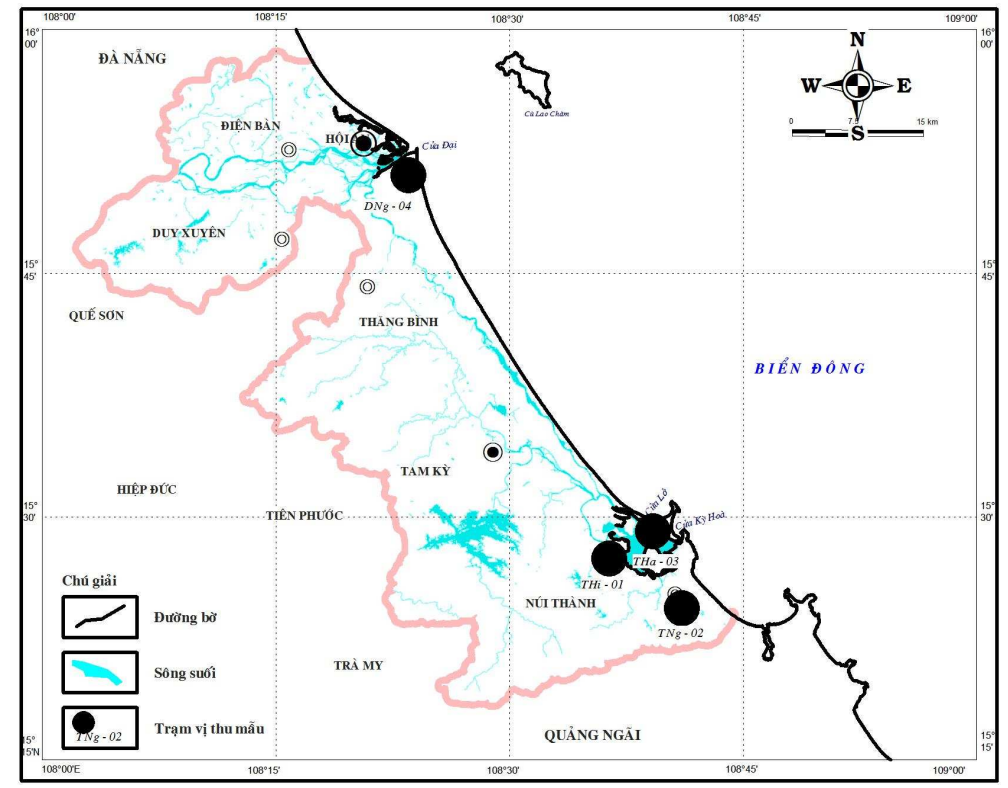

Hình 1: Sơ đồ vị trí thu mẫu ở tỉnh Quảng Nam
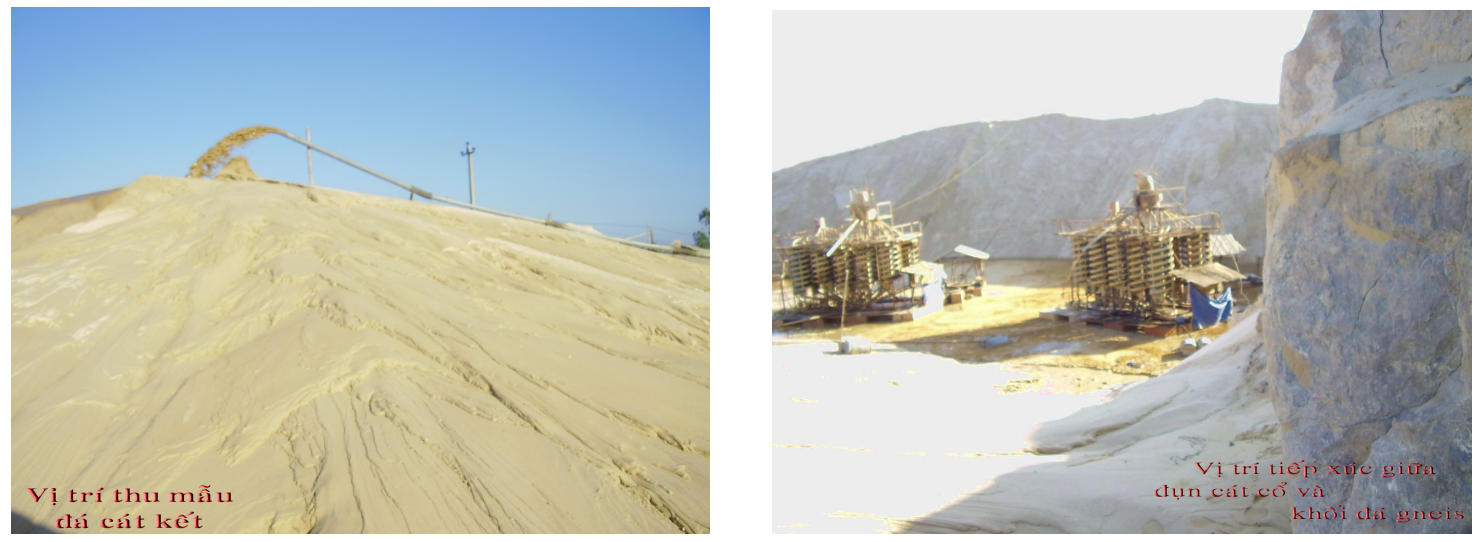

Ảnh 4: Vị trí thu mẫu đá cát kết (A) và vị trí tiếp xúc giữa đụn cát cổ và khối đá gơnai (B) tại tụ khoáng Tam Nghĩa (điểm khai thác cát quặng Ti, của Cty CP Đất Quảng) 
Riêng tại vùng bờ phía Bắc xã Tam Hải (bờ phía Nam cửa Lở) tầng đá cát kết quặng Ti lộ ra ngay dưới chân đụn cát cao 10 - 12 m. Diện tích phân bố của nó rộng hàng chục $\mathrm{m}^{2}$ với thế nằm gần như nằm ngang (ảnh 5 ).

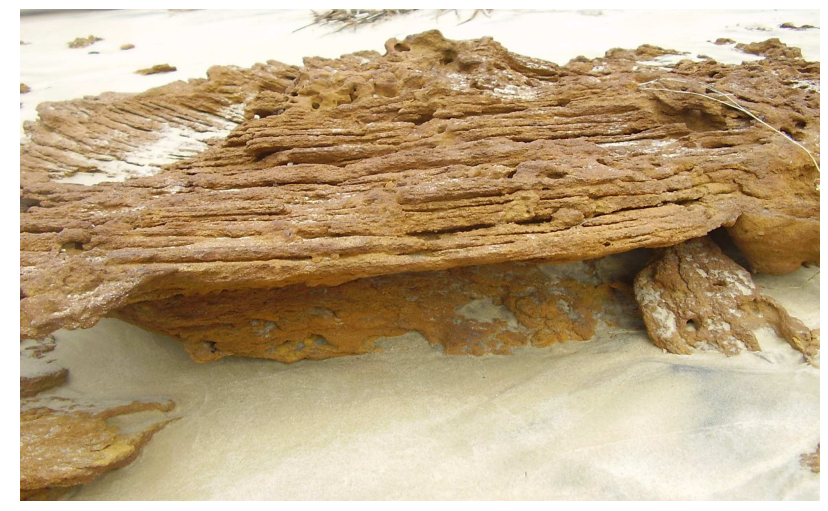

Ảnh 5: Thế nằm của đá cát kết quặng Ti tại bờ Nam cửa Lở thuộc xã Tam Hải

Các mẫu quặng Ti, là dạng đá cứng trong đá cát kết. Bên ngoài mẫu bị nhiễm gỉ phong hóa sắt, có màu vàng nâu, phần mẫu tươi có màu nâu sẫm phớt tím đen (ảnh 6). Dựa vào đặc điểm trên cho thấy, loại đá cát kết này là sản phẩm của quá trình phong hóa lục địa và có khả năng phân bố thành những dải liên tục hoặc dưới dạng da báo, dọc theo vùng bờ, dưới chân các đụn cát nguồn gốc biển - gió.

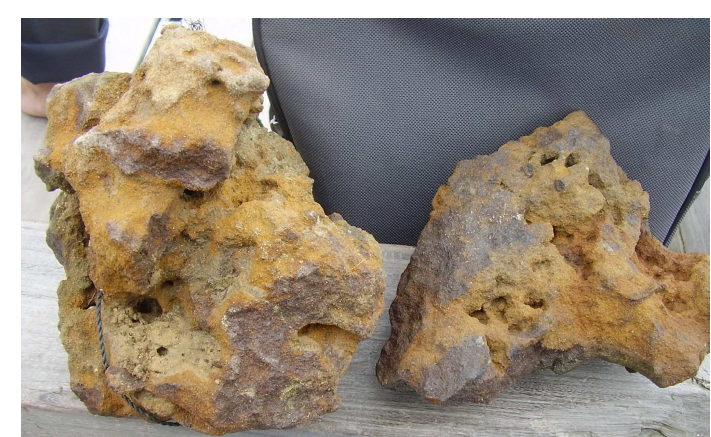

A

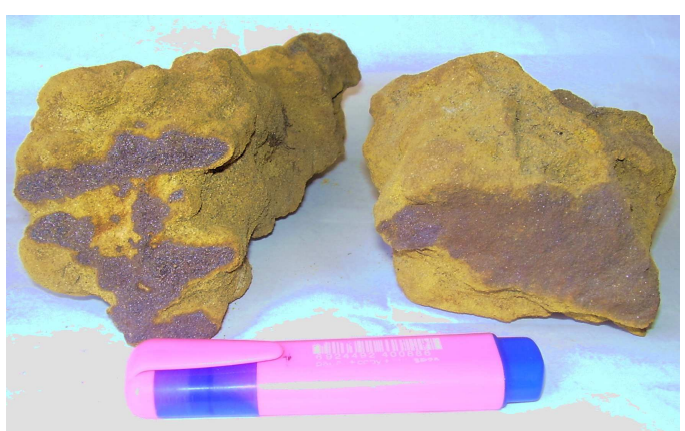

B

Ảnh 6: Quặng Ti thu được tại các khu vực thuộc vùng bờ Quảng Nam

A - Khu vực Duy Nghĩa; B - Khu vực Tam Nghĩa 


\subsection{Kết quả phân tích thạch học}

Thành phần khoáng có: Thạch anh, các khoáng vật sắt, các khoáng vật titan gắn với nhau bởi keo sắt. Các keo sắt này có thể được tạo thành trong quá trình phong hóa đá. Trong thành phần đá, các khoáng vật quặng chiếm ưu thế, cho nên tạo ra sự sẫm màu của đá. Trong các khoáng vật sắt, một số bị phong hóa và thường có kích thước hạt lớn $(0.5$ $1.0 \mathrm{~mm}$ ). Các khoáng vật Ti không bị phong hóa và thường có kích thước hạt nhỏ hơn $0.20 \mathrm{~mm}$. Trong các khoáng vật Ti, thì inmenit hoàn toàn chiếm ưu thế, rutil rất ít. Tất cả các hạt inmenit và cả rutil còn ở dạng góc cạnh. Điều này cho thấy, nguồn tiếp của các khoáng vật Ti là tại chỗ.

\subsection{Kết quả phân tích hóa học}

Bảng 2: Kết quả phân tích hóa học

\begin{tabular}{|c|c|c|c|c|c|c|c|}
\hline \multirow{2}{*}{$\begin{array}{c}\text { Ký hiệu } \\
\text { mâuu }\end{array}$} & \multirow{2}{*}{$\begin{array}{c}\text { Tên } \\
\text { gọi đá }\end{array}$} & \multicolumn{6}{|c|}{ Thành phần hóa học (\%) } \\
\cline { 3 - 8 } & $\mathbf{F e}_{\mathbf{2}} \mathbf{O}_{\mathbf{3}}$ & $\mathbf{F e}$ & $\mathbf{T i O}_{\mathbf{2}}$ & $\mathbf{T i}$ & $\mathbf{M n O}$ & $\mathbf{M n}$ \\
\hline THi - 01 & Cát kết & 21.26 & 15.08 & 8.43 & 4.94 & 0.1436 & 0.1059 \\
\hline TNg - 02 & Cát kết & 21.96 & 15.36 & 6.14 & 3.18 & 0.0773 & 0.0599 \\
\hline THa - 03 & Cát kết & 20.98 & 16.05 & 6.25 & 4.55 & 0.0734 & 0.0556 \\
\hline DNg-04 & Cát kết & 21.12 & 15.44 & 6.12 & 3.75 & 0.0823 & 0.0624 \\
\hline
\end{tabular}

Từ những kết quả phân tích và dựa vào thế nằm của các mẫu thu được có thể lý giải rằng, mẫu đá cát kết quặng Ti ở đây có nguồn gốc từ đá gơnai (gneis), trải qua quá trình phong hóa lâu dài, đã tạo thành tầng cát kết sắt mangan phong hóa. Ngay trong thành phần đá gơnai, lượng Ti cũng đã có đáng kể. Trong quá trình phong hóa, Ti được tích tụ dưới dạng khoáng inmenit nằm trong vỏ phong hóa sắt mangan lục địa. Tuy nhiên, trong quá trình phát triển của vùng bờ, lớp vỏ phong hóa này cũng đã chịu tác động của môi trường biển trong các thời kỳ biển tiến. Điều này được thể hiện, trong thành phần xi măng của đá cát kết này, ngoài xi măng sắt, còn có xi măng vôi. Như vậy, có thể nhận thấy rằng, chính lớp đá cát kết quặng Ti này, là một trong những nguồn tiếp quan trọng cho các tụ khoáng Ti trong vùng.

\section{KẾT LUẬN}

- Các mẫu đá cát kết quặng Ti thu được tại các tụ khoáng Duy Nghĩa, (huyện Duy Xuyên), Tam Hiệp, Tam Nghĩa và Tam Hải (huyện Núi Thành), tỉnh Quảng Nam là khá 
độc đáo và hiếm gặp tại các mỏ sa khoáng cũng như các tụ khoáng dọc ven bờ Quảng Nam nói riêng và ven bờ miền Trung nói chung. Mẫu thu được có nguồn gốc phong hóa lục địa từ đá gơnai. Việc nghiên cứu chi tiết đặc điểm thành phần và sự phân bố của chúng, sẽ góp phần làm sáng tỏ quá trình phát triển vùng bờ nói chung và luận giải về nguồn cung cấp quặng sa khoáng Ti ven biển nói riêng.

- Tụ khoáng Ti Duy Nghĩa, Tam Hiệp, Tam Nghĩa và Tam Hải, nằm trong hệ thống các cồn cát nguồn góc biển - gió tuổi Holocen $\left(\mathrm{mvQ}_{4}{ }^{2-3}\right)$. Quá trình thành tạo cát quặng Ti có thể diễn ra theo trình tự như sau: Biến tiến Holocen trung $\rightarrow$ phá hủy vỏ phong hóa $\rightarrow$ biển gia công lại $\rightarrow$ tái tích tụ lại quặng Ti. Như vậy, một trong những nguồn cung cấp quặng sa khoáng cho các tụ khoáng này, chính là đá cát kết quặng Ti trong lớp vỏ phong hóa $\mathrm{Fe}$ - Mn lục địa có mặt trong vùng này.

\title{
TÀI LIỆU THAM KHẢO
}

1. Trịnh Thế Hiếu, 2006. Tài nguyên khoáng sản rắn vùng bờ tỉnh Quảng Nam - Hiện trạng khai thác và vấn đề môi trường. Tạp chí KH \& CN biển, T. 6 (2006). Số 4. Tr.37 - 47 .

2. Meurig P. Jones and Marston G. Fleming, 1965. Indentification of mineral grains. pp.102. Elsevier Publishing Company Amsterdam - London - New York.

3. Smirnov V.I., 1976. Địa chất khoáng sản có ích. 688 tr. NXB. Nauka, Moscow (Nguyên bản tiếng Nga).

4. Tatarinov P.M. and Kuryakin A.E. (đồng chủ biên), 1975. Khoáng sàng học. 630 tr. NXB. Nedra, Leningrad (Nguyên bản tiếng Nga).

\section{DISCUSSION ON ORIGIN OF TITANIUM ORE ALONG COASTAL ZONE OF QUANG NAM PROVINCE (CENTRAL VIET NAM)}

\author{
TRINH THE HIEU, DO MINH TIEP, PHAM BA TRUNG
}

\footnotetext{
Summary: The titanium - ore - bearing sandstone samples from mineral deposits Duy Nghia (of Duy Xuyen district), Tam Hiep, Tam Nghia and Tam Hai (Nui Thanh district), Quang Nam province are quite original and rare for whole Central Vietnam coastal zone in general and Quang Nam province in particular.

The titanium - ore - bearing sandstone content is of quartzs, ferromagnesian minerals, and titanium minerals. The constituent is joined to each with others by ferrous cement, which
} 
formed from weathering process. The dominant content of ore in the rocks made them to turn into dark color.

The titanium - ore - bearing sandstone is just the source of the titanium deposits of Quang Nam coastal zone.

Ngày nhận bài: 22 - 10 - 2009

Ngưòi nhận xét: TS. Phùng Văn Phách 